\title{
Genetic parameters for growth, wood density and pulp yield in Eucalyptus globulus
}

\author{
João Costa e Silva • Nuno M. G. Borralho • \\ José A. Araújo • René E. Vaillancourt • Brad M. Potts
}

Received: 12 June 2008 /Revised: 30 June 2008 / Accepted: 8 July 2008 / Published online: 5 September 2008

(C) Springer-Verlag 2008

\begin{abstract}
Genetic variation and co-variation among the key pulpwood selection traits for Eucalyptus globulus were estimated for a range of sites in Portugal, with the aim of improving genetic parameters used to predict breeding values and correlated response to selection. The trials comprised clonally replicated full-sib families (eight trials) and unrelated clones (17 trials), and exhibited varying levels of pedigree connectivity. The traits studied were stem diameter at breast height, Pilodyn penetration (an indirect measure of wood basic density) and near infrared reflectance predicted pulp yield. Univariate and multivariate linear mixed models were fitted within and across sites, and
\end{abstract}

Communicated by R. Burdon

J. Costa e Silva $(\square)$

Centro de Matemática e Aplicações,

Departamento de Matemática, Instituto Superior Técnico,

Universidade Técnica de Lisboa,

Avenida Rovisco Pais,

1049-001 Lisboa, Portugal

e-mail: jmmsilva@math.ist.utl.pt

e-mail: jces@isa.utl.pt

J. Costa e Silva $\cdot$ N. M. G. Borralho

Centro de Estudos Florestais, Departamento de Engenharia

Florestal, Instituto Superior de Agronomia,

Universidade Técnica de Lisboa,

Tapada da Ajuda,

1349-017 Lisboa, Portugal

\section{J. A. Araújo}

RAIZ Forest and Paper Research Institute,

Quinta de S. Francisco, Apartado 15,

3801-50 Eixo, Portugal

R. E. Vaillancourt • B. M. Potts

School of Plant Science and Cooperative Research Centre for Forestry, University of Tasmania,

Private Bag 55, estimates of additive genetic, total genetic, environmental and phenotypic variances and covariances were obtained. All traits studied exhibited significant levels of additive genetic variation. The average estimated within-site narrowsense heritability was $0.19 \pm 0.03$ for diameter and $0.29 \pm$ 0.03 for Pilodyn penetration, and the pooled estimate for predicted pulp yield was $0.42 \pm 0.14$. When they could be tested, dominance and epistatic effects were generally not statistically significant, although broad-sense heritability estimates were slightly higher than narrow-sense heritability estimates. Averaged across trials, positive additive $(0.64 \pm 0.08)$, total genetic $(0.58 \pm 0.04)$, environmental $(0.38 \pm 0.03)$ and phenotypic $(0.43 \pm 0.02)$ correlation estimates were consistently obtained between diameter and Pilodyn penetration. This data argues for at least some form of pleiotropic relationship between these two traits and that selection for fast growth will adversely affect wood density in this population. Estimates of the across-site genetic correlations for diameter and Pilodyn penetration were high, indicating that the genotype by environment interaction is low across the range of sites tested. This result supports the use of single aggregated selection criteria for growth and wood density across planting environments in Portugal, as opposed to having to select for performance in different environments.

Keywords Eucalyptus globulus · Additive genetic variance $\cdot$ Dominance $\cdot$ Epistasis $\cdot$ Heritability .

Genetic correlation $\cdot$ Linear mixed models

\section{Introduction}

Eucalyptus globulus Labill. is the main hardwood species grown in pulpwood plantations in temperate regions of the 
world (Eldridge et al. 1993; Potts et al. 2004). Growth, wood basic density and pulp yield are the main traits used by breeders to select genotypes to maximise profit from $E$. globulus pulpwood plantations (Borralho et al. 1993; Greaves et al. 1997; Raymond and Apiolaza 2004), although on some sites survival may also be important (Chambers and Borralho 1997). This pulpwood breeding objective is closely aligned with an objective that maximises profit from combined pulpwood production and trading of sequestered carbon (Whittock et al. 2007), and is logically expected to be highly correlated with objectives for bio-energy (Núñez-Regueira et al. 2002). However, such genetic gain from multi-trait selection depends upon the level of additive genetic variability in each trait, the selection intensity and the genetic correlations among traits (Falconer and Mackay 1996).

There has been abundant evidence for significant genetic variation in growth traits in E. globulus, although most estimates may have been biased by higher narrow-sense heritability estimates from open-pollinated populations (average $\widehat{h}^{2}=0.2$ ) compared to those derived from controlled crossings $\left(\widehat{h}^{2}=0.1\right.$; Lopez et al. 2002; Li et al. 2007). The overestimation from open-pollinated progeny trials is believed to be due to the susceptibility of growth to inbreeding depression (Hardner and Potts 1995), which is expressed through variable inbreeding arising from selfing or bi-parental inbreeding under open-pollination (Hodge et al. 1996; Potts et al. 2004). E. globulus has a mixed mating system, with outcrossing rates varying between trees from $38 \%$ to $100 \%$ (Potts et al. 2008). Such variation is believed to contribute to the poor correlation reported between breeding values estimated for growth from open-pollinated compared to control-pollinated progeny (Hodge et al. 1996; Volker 2002).

Breeders estimate whole-tree wood density nondestructively using stem cores taken at breast height with a mechanical corer or by using Pilodyn penetration (Raymond et al. 1998; Muneri and Raymond 2000). Pilodyn is an instrument that shoots a pin into the tree with a constant force, and its penetration is inversely related to the density of the wood. A high genetic correlation between this indirect assessment of wood density and core basic density has been reported (Dean et al. 1990; Greaves et al. 1996; Muneri and Raymond 2000), and either measure can be used to select dense trees. Wood density does not appear to be affected by inbreeding depression (Hardner and Tibbits 1998), and heritabilities and breeding values estimated from open-pollinated and control-pollinated progenies have been similar (Volker 2002; Li et al. 2007). Wood density traits are genetically variable in E. globulus and have a higher narrow-sense heritability than growth traits (Lopez et al. 2002; Potts et al. 2004).
The percentage yield of pulp obtained from dry wood (pulp yield) is expensive to measure on an individual whole-tree basis, and this has meant that, despite its importance, there are few estimates of genetic parameters published for this trait. The development of models to predict pulp yield from near-infrared spectra derived from cores is making sampling feasible at a scale sufficient to estimate genetic parameters (Schimleck et al. 2000; Raymond et al. 2001; Downes et al. 2007). Nevertheless, the pattern and level of genetic control for pulp yield in $E$. globulus remains unclear, as current estimates of genetic parameters for this trait are scarce.

Genetic correlations are equally important in estimating the correlated response to selection in breeding programs (Falconer and Mackay 1996). Adverse genetic correlations can curtail breeding progress as, for example, a negative genetic correlation between growth and wood density would make it more difficult to select concurrently for improvement in both traits. Estimates of the genetic correlation between growth and wood density, even when measured from large progeny trials, have varied from zero to significantly adverse depending upon site (McDonald et al. 1997; Muneri and Raymond 2000; Lopez et al. 2002). Reported estimates of genetic correlations involving pulp yield have been variable, ranging from 0 to 1 with basic density and from -0.16 to -0.54 with diameter (Dean et al. 1990; Raymond et al. 2001; Apiolaza et al. 2005). However, most published estimates of additive genetic correlations amongst the key selection traits in E. globulus have been based on open-pollinated progeny trials. In these cases, the additive genetic correlation estimates involving growth may also be biased due to inbreeding depression affecting growth but not wood properties. Genetic correlations estimated from open-pollinated progenies may thus provide poor estimates of the correlated response to selection in advanced generations. Indeed, in the only direct comparison to date, the estimated genetic correlation between growth and wood density was zero in openpollinated progenies but negative in control-pollinated progenies involving the same E. globulus parents (Volker 2002). Genetic correlations between growth and other traits are therefore better estimated in fully pedigreed genetic material, especially if directly relevant to the next generation of breeding.

The present study aims to estimate the genetic correlations between growth, wood density and pulp yield in $E$. globulus using clonally replicated full-sib families and unrelated clones established across a range of sites. They are part of the advanced generation RAIZ breeding program in Portugal. The results are important for assigning suitable genetic parameter values to multivariate analyses in ongoing E. globulus breeding programs and for estimating expected genetic responses from multivariate selection. 


\section{Materials and methods}

\section{Plant material and measurements}

This study was based on measurements of growth and wood properties taken from clonally replicated E. globulus progeny derived from controlled full-sib crosses (denoted control-pollinated or CP) and/or unrelated clones (denoted UC). The parents used in the crossings and the unrelated clones were plus trees selected for overall good growth and form in commercial plantations in Portugal, and belong to what is commonly referred to as the Portuguese land race (Freeman et al. 2007).

The traits examined were breast-height diameter (DBH), a two-reading average of breast-height Pilodyn penetration under bark (PIL, using a 6-J Pilodyn wood tester with a 2.5mm striker pin) as an indirect measure of wood density, and pulp yield (PY) predicted using near infrared spectroscopy (NIR; see Appendix 1 for details). The measurement ages (in years from planting) ranged from 4 to 11 for $\mathrm{DBH}, 4$ to 10 for PIL, and 3 to 10 for PY. The samples for NIR determinations were from two increment cores (with $10 \mathrm{~mm}$ in diameter) taken at breast height in two orthogonal directions after removing the bark. The increment cores were subsequently processed for NIR analysis following the same sample preparation procedures as those described in Appendix 1.

The analyses of DBH and PIL were based on eight trials with controlled crosses (numbered 1 to 8 ) and 17 trials with unrelated clones (numbered 1 to 5 and 8 to 19). Six of the trials (i.e. trials 1 to 5 , and 8 ) had both types of plant material. The $\mathrm{CP}$ material had a sparse diallel mating design, with the average number of crosses per parent ranging from three to four amongst trials. No reciprocals and selfs were present. The number of full-sib families varied between 37 and 67 across trials. There were some full-sib families represented by a single clone (i.e. genotype) due to problems related to rooting success of the progeny's cuttings and survival in the field. For the other full-sib families, the average number of clones per family varied between three and seven amongst trials. Appendix 2 shows the number of parents and clones within full-sib families in trials 1 to 8 , as well as the connections amongst the trials for these genetic entries. For the UC material, Appendix 3 provides the number of clones in each trial, as well as the number of common clones across trials. There were only few individuals tested as both parents in the controlled crosses and clones in the UC material.

Unlike DBH, which was measured in all trees, and PIL, which was measured from an unselected proportion of the trees, PY was taken mostly from a selected subset of clones having better growth and wood density. Although care was taken to sample a few common controls within each trial, trees with poor growth and wood density were therefore poorly represented in the PY sampling. Besides trials 1 to 8, sampling for PY included an extra set of five CP trials. These five trials were genetically linked with the other CP material, but they were either too small or, as indicated by previous analyses of DBH and PIL, had no significant genetic variance for one or both of these traits. Consequently, these five trials were omitted from the set of CP trials used for the analyses of DBH and PIL. However, in order to have more PY observations for a pooled analysis (see below), all the information available for this trait was combined into a single data set. This combined PY data set also included DBH and PIL measures, and comprised 75 parents and 108 full-sib families. There were 247 clones within full-sib families and 576 ramets contained in these PY data, with most of the clones being sampled in at least two replicates in a given trial, although only around one quarter of them were present in more than one trial. Nevertheless, the majority of the sampled parents were represented across different trials. The average number of crosses per parent was three. For full-sib families with more than one clone (which represented the majority of the families), the average number of clones per family was three. The data for PY included 4-year-old DBH records from all trials except for a slower growing trial, where 6-year-old DBH measures were used. This was done to minimise variance heterogeneity in the analysis of the combined data.

\section{Field tests}

The field tests were established across a range of contrasting growing conditions in Portugal. Although climate and soil conditions varied, all trials were located in typical Mediterranean conditions, with annual precipitation below $1000 \mathrm{~mm}$, falling mostly in the winter months and having an extended dry period in the summer of up to 3-4 months. Typical productivities (mean annual increments in standing volume over bark) across sites varied but are expected to be in the range $10-15 \mathrm{~m}^{3} /$ ha per year at rotation end, which in Portugal is usually 12 years.

All trials used a randomized complete block design, except for trials 6 to 8, where a resolvable incomplete block design (i.e. alpha design viz. Williams and Matheson 1994) was used. The number of replicates and incomplete blocks ranged from four to 16 and 14 to 36 , respectively, across trials. In the CP trials, each full-sib family was normally represented in each replicate and, in order to provide a more efficient environmental sampling, the clones within full-sib families were randomly allocated to single-tree noncontiguous plots within replicates. For both CP and UC material, each clone was represented in the different replicates (i.e. with one ramet per clone and per replicate) of a trial. Details about the production of planting stock are described in Costa e Silva et al. (2004). Results from 
across-site combined analysis of single traits (i.e. DBH, PIL or height growth) have been reported elsewhere (Costa e Silva et al. 2004, 2005), using early measures from a subset of the CP trials studied here.

\section{Data analysis}

The (co)variance parameters were estimated within the framework of the general linear mixed model:

$\mathbf{y}=\mathbf{X b}+\mathbf{Z} \mathbf{u}+\mathbf{e}$

where $\mathbf{y}$ is the vector of trait observations, $\mathbf{b}$ and $\mathbf{u}$ are vectors of fixed and random effects (respectively), $\mathbf{e}$ is the vector of random residual terms, and $\mathbf{X}$ and $\mathbf{Z}$ are incidence matrices relating the observations to the model effects.

For each trait, the terms in $\mathbf{b}$ comprised fixed effects for the overall mean, trials and replicates within trials. In the analysis of PY, the vector $\mathbf{b}$ also included the age of measurement as a covariate. In the CP material, u had subvectors for additive genetic effects (pertaining to parent trees and cloned progeny), full-sib families, clones within full-sib families and (where applicable) incomplete blocks. In the UC material, u had sub-vectors for total genetic effects and (where applicable) incomplete blocks. The joint distribution of the random terms was assumed to be multivariate normal, with means and (co)variances:

$\left[\begin{array}{l}\mathbf{u} \\ \mathbf{e}\end{array}\right] \sim N\left(\left[\begin{array}{l}\mathbf{0} \\ \mathbf{0}\end{array}\right],\left[\begin{array}{cc}\mathbf{G} & \mathbf{0} \\ \mathbf{0} & \mathbf{R}\end{array}\right]\right)$

where $\mathbf{0}$ is a null matrix, $\mathbf{G}$ and $\mathbf{R}$ are (co)variance matrices corresponding to $\mathbf{u}$ and $\mathbf{e}$, respectively. Different model terms in $\mathbf{u}$ were assumed to be mutually independent, and thus $\mathbf{G}$ was defined as $\oplus_{i=1}^{j} \mathbf{G}_{i}$, where $\mathbf{G}_{i}$ is the (co)variance matrix for the $i$ th random term $(i=1 \ldots j)$ and $\oplus$ is the direct sum operation.

The (co)variance components were estimated by restricted maximum likelihood (REML, Patterson and Thompson 1971), using the average information REML algorithm (Gilmour et al. 1995) implemented in the ASREML program (Gilmour et al. 2002). The standard errors of the parameter estimates were calculated according to the general expression for the variance of a ratio, based on an approximation using Taylor series expansion (Lynch and Walsh 1998). The following analyses were carried out.

\section{Single-trait analysis}

Single-trait analysis was performed for DBH and PIL for each trial, as well as for all traits in the combined PY data. In the analyses using CP material, $\mathbf{G}_{i}$ was defined as $\mathbf{A} \sigma_{a}^{2}$ for additive genetic effects and as $\mathbf{I}_{n_{i}} \sigma_{i}^{2}$ for the other random terms, where $\mathbf{A}$ is the numerator relationship matrix
(Henderson 1984), $\mathbf{I}_{n_{i}}$ is an identity matrix of dimension $n_{i} \times n_{i}\left(n_{i}=\right.$ number of levels of the $i$ th term), $\sigma_{a}^{2}$ is the additive genetic variance and $\sigma_{i}^{2}$ is the variance associated with the $i$ th term. Depending on the random term considered, $\sigma_{i}^{2}$ is equal to $\sigma_{f}^{2}, \sigma_{c}^{2}$ or $\sigma_{b}^{2}$, where $\sigma_{f}^{2}$ is the variance specific to full-sib families, $\sigma_{c}^{2}$ is the variance among clones within full-sib families and $\sigma_{b}^{2}$ is the variance among incomplete blocks. In the CP data, observations on different ramets of a given clone were treated as repeated measurements on a single genotype, and thus A describes the additive genetic relationships among individual genotypes rather than individual trees (Costa e Silva et al. 2004, 2005). In the UC data, however, the clones were unrelated, and thus $\mathbf{G}_{i}=\mathbf{I}_{n_{g}} \sigma_{g}^{2}$, where $\sigma_{g}^{2}$ is the total genetic variance and $\mathbf{I}_{n_{g}}$ is an identity matrix of dimension $n_{g} \times n_{g}\left(n_{g}=\right.$ number of genotypes). For both types of plant material, the residual effects were defined by $\mathbf{R}=\mathbf{I}_{N} \sigma_{e}^{2}$, where $\mathbf{I}_{N}$ is an identity matrix of dimension $N \times N(N=$ number of trees $)$ and $\sigma_{e}^{2}$ is the environmental variance. In the analyses using the combined PY data, and due to the smaller number of records per trial, the incomplete block term in the model was ignored and a homogeneous variance across trials was assumed for the remaining random terms, hence $\widehat{\sigma}_{a}^{2}, \widehat{\sigma}_{f}^{2}, \widehat{\sigma}_{c}^{2}$ and $\widehat{\sigma}_{e}^{2}$ become pooled estimates for each trait. As dominance relationships are present in full-sib families with at least two genotypes, the $\widehat{\sigma}_{f}^{2}$ estimation excluded the information from families with only one genotype. This was achieved by adding to the data a factor with two levelslevel 1 coding for family sizes $=1$ and level 2 coding for family sizes $\geq 2$ - and using the ASREML model function at(factor, 2 ) to define a dummy variable that is 1 if the factor has level 2 for the observation.

For trials 1 to 8 in the $\mathrm{CP}$ data, all the interactions with replicates were ignored, as previous single-site analyses revealed that the interaction between full-sib families and replicates was never significant $(P>0.05)$, and only in trial 2 was the interaction among parents and replicates significant at the $5 \%$ level for both traits. The linear model used in the analysis of the combined PY data was also simplified by omitting interactions between trials and additive or non-additive genetic effects (i.e. assuming no genotype by environment interaction). These interaction effects were also found to be non-significant $(P>0.05)$ in preliminary analyses of all the traits in the combined PY data, which may partly reflect the lack of sufficient information for estimating their magnitude and detecting statistical significance.

Based on the variance component estimates mentioned above, approximations of dominance $\left(\sigma_{D}^{2}\right)$ and epistatic $\left(\sigma_{I}^{2}\right)$ variances were calculated as $\widehat{\sigma}_{D}^{2}=4 \widehat{\sigma}_{f}^{2}$ and $\widehat{\sigma}_{I}^{2}=\widehat{\sigma}_{c}^{2}-3 \widehat{\sigma}_{f}^{2}$, respectively (Costa e Silva et al. 2004, 2005). This assumes that non-random environmental effects common to ramets of the same clone (i.e. "C effects", 
Libby and Jund 1962) are negligible, and low-order interloci interactions represent a small portion of the total epistasis. From the CP material, trait estimates of narrowsense heritability $\left(\widehat{h}^{2}\right)$, dominance ratio $\left(\widehat{D}^{2}\right)$ and epistatic ratio $\left(\widehat{I}^{2}\right)$ were obtained as $\widehat{\sigma}_{a}^{2} / \widehat{\sigma}_{P}^{2}, \widehat{\sigma}_{D}^{2} / \widehat{\sigma}_{P}^{2}$ and $\widehat{\sigma}_{I}^{2} / \widehat{\sigma}_{P}^{2}$ (respectively), where $\sigma_{P}^{2}$ is the phenotypic variance, estimated as $\widehat{\sigma}_{P}^{2}=\widehat{\sigma}_{a}^{2}+\widehat{\sigma}_{D}^{2}+\widehat{\sigma}_{I}^{2}+\widehat{\sigma}_{e}^{2}$. A partition of additive and non-additive genetic parameters based on variance components estimated from an individual genotype (i.e. clone) statistical model, described as above for the CP data, has also been applied in the analysis of clonally replicated progeny tests of other forest tree species (e.g. Kumar 2006; Baltunis et al. 2008; Callister and Collins 2008; Weng et al. 2008). From the UC material, trait estimates of broad-sense heritability $\left(\widehat{H}^{2}\right)$ were obtained by $\widehat{\sigma}_{g}^{2} / \widehat{\sigma}_{P}^{2}$, where $\widehat{\sigma}_{P}^{2}=\widehat{\sigma}_{g}^{2}+\widehat{\sigma}_{e}^{2}$. Independent $\widehat{H}^{2}$ values can also be estimated using the CP material by $\widehat{h}^{2}+\widehat{D}^{2}+\widehat{I}^{2}$.

By default, the method for obtaining REML estimates attempts to keep the value of a variance in the theoretical parameter space. However, under the individual genotype model applied in this study, constraining $\widehat{\sigma}_{c}^{2}$ to be positive was found to bias the other variance estimates ( $\widehat{\sigma}_{a}^{2}$ in particular), when compared with results obtained by using a parameterisation based on the classical Griffing's (1956) model for diallel mating designs and extended to include clonal replication (e.g. Stonecypher and McCullough 1986; Mullin and Park 1992). Conversely, constraining $\widehat{\sigma}_{f}^{2}$ to remain positive did not appear to cause bias in the other variance estimates. Therefore, in our analyses using an individual genotype model, equivalence (i.e. the same REML loglikelihood) with the Griffing's model was achieved by removing non-negative restrictions on $\widehat{\sigma}_{c}^{2}$. For purposes of genetic parameter and $\widehat{\sigma}_{P}^{2}$ estimations, $\widehat{\sigma}_{f}^{2}$ and the associated $\widehat{\sigma}_{D}^{2}$ were assumed to be zero when $\widehat{\sigma}_{f}^{2}$ was constrained to remain positive at the zero bound; in addition, $\widehat{\sigma}_{I}^{2}$ was assumed to be zero when $\widehat{\sigma}_{c}^{2}$ was negative. One-tailed likelihood ratio (LR) tests (Stram and Lee 1994) were used to assess the statistical significance of $\widehat{\sigma}_{a}^{2}$ and $\widehat{\sigma}_{g}^{2}$, as well as $\widehat{\sigma}_{f}^{2}$ and $\widehat{\sigma}_{c}^{2}$ when these variances had positive estimates.

\section{Bivariate analysis of trait pairs}

Bivariate analysis was performed for DBH and PIL for each trial, as well as for all trait pairs in the combined PY data. In the analyses using CP material, the (co)variance matrices $\mathbf{G}$ and $\mathbf{R}$ were defined as:

$$
\begin{aligned}
\mathbf{G}= & {\left[\begin{array}{ll}
\mathbf{A} \sigma_{a_{k}}^{2} & \mathbf{A} \sigma_{a_{k, l}} \\
\mathbf{A} \sigma_{a_{k, l}} & \mathbf{A} \sigma_{a_{l}}^{2}
\end{array}\right] \oplus\left[\begin{array}{ll}
\mathbf{I}_{n_{f}} \sigma_{f_{k}}^{2} & \mathbf{0} \\
\mathbf{0} & \mathbf{I}_{n_{f}} \sigma_{f_{l}}^{2}
\end{array}\right] } \\
& \oplus\left[\begin{array}{ll}
\mathbf{I}_{n_{c}} \sigma_{c_{k}}^{2} & \mathbf{0} \\
\mathbf{0} & \mathbf{I}_{n_{c}} \sigma_{c_{l}}^{2}
\end{array}\right] \oplus\left[\begin{array}{ll}
\mathbf{I}_{n_{b}} \sigma_{b_{k}}^{2} & \mathbf{I}_{n_{b}} \sigma_{b_{k, l}} \\
\mathbf{I}_{n_{b}} \sigma_{b_{k, l}} & \mathbf{I}_{n_{b}} \sigma_{b_{l}}^{2}
\end{array}\right]
\end{aligned}
$$

$\mathbf{R}=\left[\begin{array}{ll}\mathbf{I}_{N} \sigma_{e_{k}}^{2} & \mathbf{I}_{N} \sigma_{e_{k, l}} \\ \mathbf{I}_{N} \sigma_{e_{k, l}} & \mathbf{I}_{N} \sigma_{e_{l}}^{2}\end{array}\right]$

where $k$ and $l$ refer to two traits, $\sigma_{k, l}$ denotes the covariance between the two traits, $\mathbf{I}$ is an identity matrix of dimension dependent on the random term considered, and $\mathbf{A}, \mathbf{0}, \sigma_{a}^{2}, \sigma_{f}^{2}$, $\sigma_{c}^{2}, \sigma_{b}^{2}$ and $\sigma_{e}^{2}$ are defined as before. In this sense, $\mathbf{G}$ accounted for variance heterogeneity in the family and clones within full-sib families effects but assumed that the respective trait covariances (and associated correlations) were zero. Single-site analyses indicated that the variances for these terms were generally small and statistically non-significant (see "Results and discussion"), which suggested that it would not be meaningful to estimate the respective trait correlations. The $\mathbf{G}_{i}$ matrices pertaining to these two random terms were not fitted in the bivariate analysis using the UC data; apart from this, the $\mathbf{G}$ and $\mathbf{R}$ (co)variance matrices were defined in the same way as for the CP material, with $\sigma_{g}^{2}$ and $\mathbf{I}_{n_{g}}$ replacing $\sigma_{a}^{2}$ and $\mathbf{A}$, respectively. The $\mathbf{G}_{i}$ matrix relating to incomplete block terms was fitted only where appropriate (i.e. trials 6,7 and 8), and it was ignored in the analyses using the combined PY data. Additive or total genetic correlations, as well as environmental and phenotypic correlations, were estimated according to standard formulae (Falconer and Mackay 1996). For the CP material, the equation used in the estimation of the phenotypic correlation ignored in its numerator the sums from trait covariances due to full-sib families and clones within full-sib families.

A bivariate multi-site analysis of DBH and PIL was also carried out by using simultaneously the information from all eight $\mathrm{CP}$ or $17 \mathrm{UC}$ trials, in order to obtain common estimates of within- and across-site correlations between traits for genetic effects, as well as to assess the magnitude of genotype by environment $(\mathrm{G} \times \mathrm{E})$ interaction by estimating a common genetic correlation between sites for a given trait. In the analysis of the $\mathrm{CP}$ material, the matrix $\mathbf{G}_{i}$ for additive genetic terms was defined as:

$$
\left(\left[\begin{array}{ll}
D_{k} & 0 \\
0 & D_{1}
\end{array}\right]\left[\begin{array}{ll}
C_{k} & C_{k, l} \\
C_{l, k} & C_{l}
\end{array}\right]\left[\begin{array}{ll}
D_{k} & 0 \\
0 & D_{l}
\end{array}\right]\right) \otimes A
$$

where, for a given trait $k$ or $l$ and matrices of dimension $8 \times 8$, $\mathbf{D}_{\mathbf{k}}$ and $\mathbf{D}_{\mathbf{l}}$ are diagonal matrices of (heterogeneous) trial genetic standard deviations, and $\mathbf{C}_{\mathbf{k}}$ and $\mathbf{C}_{\mathbf{l}}$ are across-site genetic correlation matrices; for genetic relationships between the two traits, $\mathbf{C}_{\mathbf{k}, \mathbf{l}}\left(=\mathbf{C}_{\mathbf{l}, \mathbf{k}}^{\prime}\right)$ is a matrix with correlations within (on the diagonal) and across (on the off-diagonal) trials; $\otimes$ denotes the Kronecker product. A similar definition of $\mathbf{G}_{i}$ was applied for the total genetic effects in the UC data, with the $\mathbf{D}$ and $\mathbf{C}$ matrices being now of dimension $17 \times 17$ and $\mathbf{I}_{n_{g}}$ replacing A. Four restrictions were imposed on these analyses, which entailed two constraints to equalise the elements within $\mathbf{C}_{\mathbf{k}}$ and $\mathbf{C}_{\mathbf{l}}$, and two constraints within $\mathbf{C}_{\mathbf{k}, \mathbf{l}}$ to equalise the respective diagonal and off-diagonal elements. The remaining 
fitted effects in $\mathbf{u}$ and residuals in $\mathbf{e}$ were assumed to be uncorrelated across trials, and thus $\mathbf{G}_{i}=\oplus_{p=1}^{q} \Sigma_{i_{p}} \otimes \mathbf{I}_{n_{i}}$ and $\mathbf{R}=\oplus_{p=1}^{q} \Sigma_{e_{p}} \otimes \mathbf{I}_{N_{p}}$, where $\Sigma_{i_{p}}$ and $\Sigma_{e_{p}}$ are (co)variance matrices for the $i$ th random term and residual effects (respectively) in the $p$ th trial $(p=1 \ldots q=8$ or 17$)$. In this sense, and due to the reasons mentioned above, all covariances involving sites and/or traits were ignored for full-sib families and clones within full-sib families. Moreover, to avoid estimation problems related to a non-positive definite $\mathbf{G}$ matrix in the multi-site analysis, the trial variances for these two terms were constrained to remain fixed at the estimates obtained under single-site analysis.

For the additive or total genetic effects, two-tailed LR tests were used to evaluate whether an estimated trait correlation deviated significantly from zero. This was done by using a parameterisation of $\mathbf{G}_{i}$ based on a correlation form and constraining the correlation parameter to be zero under the null hypothesis to be tested. In the bivariate multi-site analysis of DBH and PIL, two-tailed LR tests were also applied to assess whether a common correlation between traits within trials was significantly different from that across trials, and one-tailed LR tests were carried out to evaluate whether a common across-site correlation for a given trait was significantly lower than one.

\section{Results and discussion}

\section{Diameter}

The trends in mean diameter over time across the several trials, and for both the CP and UC types of plant material, followed a common linear trend with age (not shown), suggesting relatively similar growing conditions across sites and ages. Estimates of variances and associated genetic parameters for DBH at each site are listed in Table 1 for the CP material and in Table 2 for the UC material. Statistically significant $(P \leq 0.05)$ additive $(\mathrm{CP})$ or total genetic (UC) variation for DBH was detected in all trials (Tables 1 and 2).

DBH appears to be under moderate additive genetic control in this population. Within trials, $\widehat{h}^{2}$ ranged between 0.11 and 0.35 (Table 1). The average of these estimates $\left(\widehat{h}^{2}=0.19 \pm 0.03, n=8\right)$ was slightly below the average for those derived from open-pollinated progeny trials of $E$. globulus (i.e. $\widehat{h}^{2}=0.21$, as reviewed by Lopez et al. 2002) but is larger than previously reported for other full-sib family trials (e.g. $\widehat{h}^{2}=0.12$ averaged across five trials aged 6 years, Volker 2002; $\widehat{h}^{2}=0.12$ averaged across nine second-generation Australian breeding trials aged between 2 and 5 years, Li et al. 2007; $\widehat{h}^{2}=0.17$, one trial aged 6 years, Volker et al. 2008). Most $\widehat{h}^{2}$ values reported in $E$. globulus refer to additive genetic effects within genetic groups, as defined by the native stand provenance (Volker 2002) or the racial classification of Dutkowski and Potts (1999). The Portuguese land race selections of E. globulus that comprise the RAIZ breeding population analysed here are known to have diverse native origins (Freeman et al. 2007). While racial differentiation in growth traits is relatively low, it is statistically significant (Potts and Jordan 1994; McDonald et al. 1997; Potts et al. 2004), and some confounding of background genetic group effects may explain the higher $\widehat{h}^{2}$ observed in the present study. Other explanations include a lower non-additive genetic variance (see below).

Table 1 Estimated means, variances and derived genetic parameters from single-site analysis of breast-height diameter (DBH) measured in $E$. globulus trials with clonally replicated progeny from controlled crosses

\begin{tabular}{|c|c|c|c|c|c|c|c|c|c|c|c|}
\hline \multirow[t]{2}{*}{ Trial } & \multirow[t]{2}{*}{ Age (years) } & \multirow[t]{2}{*}{ Mean $(\mathrm{cm})$} & \multicolumn{5}{|l|}{ Variances } & \multicolumn{4}{|c|}{ Genetic parameters } \\
\hline & & & $\widehat{\sigma}_{a}^{2}$ & $\widehat{\sigma}_{D}^{2}$ & $\widehat{\sigma}_{I}^{2}$ & $\widehat{\sigma}_{e}^{2}$ & $\widehat{\sigma}_{P}^{2}$ & $\widehat{h}^{2}$ & $\widehat{D}^{2}$ & $\widehat{I}^{2}$ & $\widehat{H}^{2}$ \\
\hline 1 & 7 & 14.2 & $0.84, P=0.004$ & $a$ & $1.24, P=0.012$ & 3.63 & 5.71 & $0.15(0.09)$ & $\mathrm{NE}$ & $0.22(0.08)$ & 0.37 \\
\hline 2 & 7 & 14.9 & $1.11, P<0.001$ & $a$ & $b$ & 8.72 & 9.83 & $0.11(0.05)$ & $\mathrm{NE}$ & $\mathrm{NE}$ & 0.11 \\
\hline 3 & 4 & 10.5 & $0.66, P=0.034$ & $0.64, P>0.05$ & $c$ & 4.61 & 5.91 & $0.11(0.08)$ & $0.11(0.13)$ & $\mathrm{NE}$ & 0.22 \\
\hline 4 & 6 & 10.0 & $0.89, P=0.001$ & $a$ & $b$ & 3.64 & 4.53 & $0.20(0.10)$ & $\mathrm{NE}$ & $\mathrm{NE}$ & 0.20 \\
\hline 5 & 6 & 10.7 & $1.16, P<0.001$ & $a$ & $b$ & 5.75 & 6.91 & $0.17(0.08)$ & NE & $\mathrm{NE}$ & 0.17 \\
\hline 6 & 4 & 10.0 & $0.97, P<0.001$ & $a$ & $0.04, P>0.05$ & 2.89 & 3.90 & $0.25(0.12)$ & $\mathrm{NE}$ & $0.01(0.10)$ & 0.26 \\
\hline 7 & 4 & 6.3 & $0.30, P=0.015$ & $0.05, P>0.05$ & $c$ & 1.23 & 1.58 & $0.19(0.10)$ & $0.03(0.15)$ & $\mathrm{NE}$ & 0.22 \\
\hline 8 & 4 & 9.8 & $1.31, P<0.001$ & $0.11, P>0.05$ & $b$ & 2.30 & 3.72 & $0.35(0.10)$ & $0.03(0.11)$ & $\mathrm{NE}$ & 0.38 \\
\hline
\end{tabular}

$\widehat{\sigma}_{a}^{2}, \widehat{\sigma}_{D}^{2}, \widehat{\sigma}_{I}^{2}, \widehat{\sigma}_{e}^{2}, \widehat{\sigma}_{P}^{2}=$ estimated additive genetic, dominance, epistatic, environmental and phenotypic variances, respectively; $\widehat{h}^{2}, \widehat{D}^{2}, \widehat{I}^{2}=$ estimated narrow-sense heritability, dominance and epistatic ratios, respectively; $\widehat{H}^{2}=\widehat{h}^{2}+\widehat{D}^{2}+\widehat{I}^{2}=$ estimated broad-sense heritability. For $\widehat{h}^{2}$, $\widehat{D}^{2}$ and $\widehat{I}^{2}$, the approximate standard errors are given in parenthesis. The $P$ values refer to likelihood ratio tests, which were carried out to test the departure of $\widehat{\sigma}_{a}^{2}$, as well as the variance specific to full-sib families ( $P$ value in the $\widehat{\sigma}_{D}^{2}$ column) and the variance among clones within full-sib families ( $P$ value in the $\widehat{\sigma}_{I}^{2}$ column), from zero.

$N E$ not estimated and assumed to be zero.

a $\widehat{\sigma}_{f}^{2}$ constrained to remain positive at the zero bound.

$\mathrm{b} \widehat{\sigma}_{c}^{2}$ allowed to be negative, but it was close to zero.

${ }^{\mathrm{c}} \widehat{\sigma}_{I}^{2}=\widehat{\sigma}_{c}^{2}-3 \widehat{\sigma}_{f}^{2}$ was negative, but it was close to zero. 
Table 2 Estimated means, variances and derived genetic parameters from single-site analysis of breast-height diameter (DBH) measured in $E$. globulus trials with unrelated clones

\begin{tabular}{|c|c|c|c|c|c|c|}
\hline Trial & Age (years) & Mean $(\mathrm{cm})$ & $\widehat{\sigma}_{g}^{2}$ & $\widehat{\sigma}_{e}^{2}$ & $\widehat{\sigma}_{P}^{2}$ & $\widehat{H}^{2}$ \\
\hline 1 & 7 & 13.5 & $2.49, P<0.001$ & 3.42 & 5.91 & $0.42(0.08)$ \\
\hline 2 & 7 & 14.9 & $1.37, P=0.007$ & 8.82 & 10.19 & $0.13(0.07)$ \\
\hline 3 & 4 & 10.1 & $0.89, P<0.001$ & 3.57 & 4.46 & $0.20(0.07)$ \\
\hline 4 & 6 & 9.6 & $1.26, P<0.001$ & 3.13 & 4.39 & $0.29(0.07)$ \\
\hline 5 & 6 & 10.1 & $1.41, P<0.001$ & 5.66 & 7.07 & $0.20(0.08)$ \\
\hline 8 & 4 & 8.9 & $0.73, P=0.001$ & 2.05 & 2.78 & $0.26(0.11)$ \\
\hline 9 & 6 & 12.3 & $1.16, P<0.001$ & 6.77 & 7.93 & $0.15(0.05)$ \\
\hline 10 & 7 & 12.7 & $0.81, P<0.001$ & 3.92 & 4.73 & $0.17(0.05)$ \\
\hline 11 & 10 & 17.6 & $1.70, P<0.001$ & 7.04 & 8.74 & $0.19(0.04)$ \\
\hline 12 & 11 & 19.1 & $3.94, P<0.001$ & 6.50 & 10.44 & $0.38(0.06)$ \\
\hline 13 & 8 & 15.1 & $4.11, P<0.001$ & 4.04 & 8.15 & $0.50(0.06)$ \\
\hline 14 & 6 & 11.8 & $1.01, P=0.003$ & 6.82 & 7.83 & $0.13(0.06)$ \\
\hline 15 & 7 & 12.1 & $1.04, P<0.001$ & 2.51 & 3.55 & $0.29(0.05)$ \\
\hline 16 & 7 & 10.6 & $0.97, P<0.001$ & 4.30 & 5.27 & $0.18(0.05)$ \\
\hline 17 & 6 & 10.7 & $1.06, P<0.001$ & 3.54 & 4.60 & $0.23(0.05)$ \\
\hline 18 & 10 & 12.6 & $1.15, P<0.001$ & 4.46 & 5.61 & $0.20(0.06)$ \\
\hline 19 & 9 & 17.7 & $1.56, P<0.001$ & 10.68 & 12.24 & $0.13(0.04)$ \\
\hline
\end{tabular}

$\widehat{\sigma}_{g}^{2}, \widehat{\sigma}_{e}^{2}, \widehat{\sigma}_{P}^{2}=$ estimated total genetic, environmental and phenotypic variances, respectively; $\widehat{H}^{2}=$ estimated broad-sense heritability. For $\widehat{H}^{2}$, the approximate standard errors are given in parenthesis. The $P$ values refer to likelihood ratio tests, which were carried out to test the departure of $\widehat{\sigma}_{g}^{2}$ from zero.

There are two independent lines of evidence to suggest that non-additive genetic effects for DBH are small in the current population. The first line is derived from the CP trials, where $\widehat{D}^{2}$ and $\widehat{I}^{2}$ ratios were close to zero for most of the trials (Table 1). The proportion of the total phenotypic variance attributable to non-additive genetic variance averaged only $0.05 \pm 0.03$ (i.e. $\widehat{D}^{2}=$ $0.02 \pm 0.01$ and $\widehat{I}^{2}=0.03 \pm 0.03, n=8$ ). The average of the ratio of non-additive to additive variance was $0.34 \pm$ 0.20 , and non-additive to total genetic variance was $0.17 \pm$ 0.08 . Low non-additive effects on DBH were also reported following analysis of a subset of the present trials (Costa e Silva et al. 2004). It is not clear from the data whether dominance or epistasis would be the most important source of the non-additive effects. Two trials had positive variances for epistasis and three trials had positive dominance variances, but only in one of them were the variances associated with these non-additive effects significantly different from zero $(P \leq 0.05)$ and that was for $\widehat{\sigma}_{c}^{2}$ in trial 1. Direct estimates of non-additive genetic effects are notoriously hard to calculate with accuracy (Chang et al. 1990), requiring large sample sizes and pedigree relationships that are rarely available for forest trees. Also, various spurious effects may be confounded with their estimation. As mentioned in "Materials and methods", the derivation of dominance and epistatic variances from the REML variance component estimates (i.e. $\widehat{\sigma}_{f}^{2}$ and $\widehat{\sigma}_{c}^{2}$ ) assumed that $\mathrm{C}$ effects among clones (which may be due to factors such as the age or the environment of the original ortet) were absent or negligible. However, when present, $\mathrm{C}$ effects among clones may inflate estimates of among-clone variances within full-sib families (Libby and Jund 1962; Burdon and Shelbourne 1974), hence causing the estimates of epistatic variances to be upwardly biased. Pedigree errors in the data are another potential problem. Wrong family classification or contaminations in a controlled cross will cause upward bias in the estimates of dominance effects. Although all of these situations are possible, their importance in the current data is thought to be small given the non-significant and low values obtained in general for $\widehat{\sigma}_{f}^{2}$ and $\widehat{\sigma}_{c}^{2}$. Indeed, the average $\widehat{D}^{2}$ found here is lower than other studies of DBH in E. globulus where they have been estimated from seedling as opposed to clonal full-sib family trials. Using data from five trials aged 6 years, Volker (2002) reported an average $\widehat{D}^{2}$ of 0.14 ; however, the expression of dominance was highly variable amongst individual trials (i.e. $\widehat{D}^{2}$ ranging from 0.05 to 0.31 ), with $\widehat{D}^{2}$ being significantly different from zero in two trials only. In a detailed study of one of these trials (Volker et al. 2008), E. globulus showed a low but relatively stable level of dominance variation over a similar age range as the present trials (i.e. $\widehat{D}^{2}$ varying between 0.05 to 0.08 from ages 4 to 10 years). The ratio of dominance to additive variance reported for early age DBH in an Australian second-generation E. globulus breeding population by $\mathrm{Li}$ et al. (2007) was significantly 
greater than zero and markedly higher than our estimate (1 versus 0.34$)$. Nevertheless, $95 \%$ of the families in their population were derived from crossing parents from different subraces, and dominance effects could not be separately estimated for intra- and inter-subrace crosses (Li et al. 2007). Thus, the significant dominance variation in the population of $\mathrm{Li}$ et al. (2007) could be the result of significant (Volker et al. 2008), potentially differential (e.g. Vaillancourt et al. 1995), heterotic effects arising from inter-subrace crossing. There is also the possibility of higher dominance effects within inter-subrace crosses as reported by Hodge et al. (1996) and Vaillancourt et al. (1995) for 2-year-old stem volume, although this effect was not detected for DBH (Volker et al. 2008).

The second line of evidence for low non-additive genetic variation for DBH comes from comparing genetic parameter estimates obtained from CP (Table 1) and UC material (Table 2). When both CP and UC material are in the same trial (i.e. trials 1 to 5 and 8), the average $\widehat{h}^{2}(0.18 \pm 0.04, n=$ 6) is only slightly lower than the average $\widehat{H}^{2}$ derived from the UC material in the same trial $(0.25 \pm 0.04, n=6)$. A similar tendency is observed when considering the averages of $\widehat{h}^{2}$ and $\widehat{H}^{2}$ across all CP and UP trials (i.e. $\widehat{h}^{2}=0.19 \pm 0.03, n=8$, versus $\widehat{H}^{2}=0.24 \pm 0.03, n=17$ ), with the difference between the two parameters being equal to the average proportion of the total phenotypic variance attributable to non-additive genetic variance, as estimated from the CP material (i.e. $0.05 \pm 0.03, n=8$ ). In trial 8, the $\widehat{h}^{2}$ estimated from the CP material $(0.35 \pm 0.10)$ actually exceeded the $\widehat{H}^{2}$ estimated from the UC material $(0.26 \pm$ 0.11 ), but their calculated standard errors indicate that the difference is not statistically significant and could arise through there being few common links between the CP parents and the unrelated clones.

\section{Pilodyn}

The trial means of the PIL measurements ranged between 7.8 and $14.1 \mathrm{~mm}$ across all the experiments analysed (Tables 3 and 4). This represented a considerable variation for PIL, but it was weakly related with trial age (i.e. correlations of -0.30 and -0.21 for the $\mathrm{CP}$ and UC material, respectively), consistent with the general trend that wood density tends to increase in older trees (Zobel and Sprague 1998; Raymond 2002).

Statistically significant $(P \leq 0.01)$ additive $(\mathrm{CP})$ or total genetic (UC) variation for PIL was detected in all trials (Tables 3 and 4). The $\widehat{h}^{2}$ ranged between 0.13 and 0.40 , and averaged $0.29 \pm 0.03(n=8$, Table 3$)$. These estimates are in general lower than those reported for PIL in several studies of open-pollinated progeny trials of E. globulus (range= 0.28 to 0.41 , McDonald et al. 1997 ; range $=0.43$ to 0.52 , Lopez et al. 2002), but are comparable to those (range $=$ 0.13 to 0.27 ) of Muneri and Raymond (2000) and estimates reported from other CP trials (see below). As noted elsewhere (Raymond 2002), $\widehat{h}^{2}$ values for PIL seem to be smaller than estimates for basic density in eucalypts.

Unlike $\mathrm{DBH}$, all eight $\mathrm{CP}$ trials had non-zero variance components associated with one or the other non-additive genetic effect for PIL, although most of these estimates were not significantly $(P>0.05)$ different from zero (Table 3$)$. The resulting averages of the $\widehat{D}^{2}(0.02 \pm 0.01, n=8)$ and $\widehat{I}^{2}(0.06 \pm$

Table 3 Estimated means, variances and derived genetic parameters from single-site analysis of breast-height Pilodyn readings (PIL) measured in E. globulus trials with clonally replicated progeny from controlled crosses

\begin{tabular}{|c|c|c|c|c|c|c|c|c|c|c|c|}
\hline \multirow[t]{2}{*}{ Trial } & \multirow[t]{2}{*}{ Age (years) } & \multirow[t]{2}{*}{ Mean (mm) } & \multicolumn{5}{|l|}{ Variances } & \multicolumn{4}{|c|}{ Genetic parameters } \\
\hline & & & $\hat{\sigma}_{a}^{2}$ & $\hat{\sigma}_{D}^{2}$ & $\hat{\sigma}_{I}^{2}$ & $\hat{\sigma}_{e}^{2}$ & $\hat{\sigma}_{P}^{2}$ & $\widehat{h}^{2}$ & $\widehat{D}^{2}$ & $\widehat{I}^{2}$ & $\widehat{H}^{2}$ \\
\hline 1 & 7 & 12.0 & $1.20, P<0.001$ & $0.14, P>0.05$ & $0.19, P>0.05$ & 1.46 & 2.99 & $0.40(0.15)$ & $0.05(0.17)$ & $0.06(0.17)$ & 0.51 \\
\hline 2 & 4 & 11.5 & $0.48, P<0.001$ & $a$ & $0.33, P=0.05$ & 2.98 & 3.79 & $0.13(0.06)$ & $\mathrm{NE}$ & $0.09(0.05)$ & 0.22 \\
\hline 3 & 6 & 12.0 & $1.31, P<0.001$ & $0.03, P>0.05$ & $b$ & 2.35 & 3.69 & $0.35(0.14)$ & $0.01(0.16)$ & $\mathrm{NE}$ & 0.36 \\
\hline 4 & 6 & 8.0 & $0.71, P<0.001$ & $a$ & $0.06, P>0.05$ & 1.90 & 2.67 & $0.27(0.13)$ & $\mathrm{NE}$ & $0.02(0.10)$ & 0.29 \\
\hline 5 & 6 & 12.2 & $0.89, P<0.001$ & $a$ & $0.13, P>0.05$ & 2.31 & 3.33 & $0.27(0.14)$ & $\mathrm{NE}$ & $0.04(0.11)$ & 0.31 \\
\hline 6 & 5 & 11.4 & $0.86, P=0.002$ & $a$ & $0.21, P>0.05$ & 2.36 & 3.43 & $0.25(0.12)$ & $\mathrm{NE}$ & $0.06(0.11)$ & 0.31 \\
\hline 7 & 5 & 10.7 & $1.19, P<0.001$ & $a$ & $0.37, P>0.05$ & 1.85 & 3.41 & $0.35(0.14)$ & $\mathrm{NE}$ & $0.11(0.12)$ & 0.46 \\
\hline 8 & 4 & 14.1 & $0.53, P=0.010$ & $0.13, P>0.05$ & $0.22, P>0.05$ & 0.77 & 1.65 & $0.32(0.16)$ & $0.08(0.22)$ & $0.13(0.18)$ & 0.53 \\
\hline
\end{tabular}

$\widehat{\sigma}_{a}^{2}, \widehat{\sigma}_{D}^{2}, \widehat{\sigma}_{I}^{2}, \widehat{\sigma}_{e}^{2}, \widehat{\sigma}_{P}^{2}=$ estimated additive genetic, dominance, epistatic, environmental and phenotypic variances, respectively; $\widehat{h}^{2}, \widehat{D}^{2}, \widehat{I}^{2}=$ estimated narrow-sense heritability, dominance and epistatic ratios, respectively; $\widehat{H}^{2}=\widehat{h}^{2}+\widehat{D}^{2}+\widehat{I}^{2}=$ estimated broad-sense heritability. For $\widehat{h}^{2}$, $\widehat{D}^{2}$ and $\widehat{I}^{2}$, the approximate standard errors are given in parenthesis. The $P$ values refer to likelihood ratio tests, which were carried out to test the departure of $\widehat{\sigma}_{a}^{2}$, as well as the variance specific to full-sib families ( $P$ value in the $\widehat{\sigma}_{D}^{2}$ column) and the variance among clones within full-sib families ( $P$ value in the $\widehat{\sigma}_{I}^{2}$ column), from zero.

$N E$ not estimated and assumed to be zero.

${ }^{\mathrm{a}} \widehat{\sigma}_{f}^{2}$ constrained to remain positive at the zero bound.

$\mathrm{b} \widehat{\sigma}_{c}^{2}$ allowed to be negative, but it was close to zero. 
Table 4 Estimated means, variances and derived genetic parameters from single-site analysis of breast-height Pilodyn readings (PIL) measured in E. globulus trials with unrelated clones

\begin{tabular}{|c|c|c|c|c|c|c|}
\hline Trial & Age (years) & Mean (mm) & $\widehat{\sigma}_{g}^{2}$ & $\widehat{\sigma}_{e}^{2}$ & $\widehat{\sigma}_{P}^{2}$ & $\widehat{H}^{2}$ \\
\hline 1 & 7 & 11.3 & $1.41, P<0.001$ & 1.67 & 3.08 & $0.46(0.08)$ \\
\hline 2 & 4 & 11.4 & $1.42, P<0.001$ & 2.30 & 3.72 & $0.38(0.08)$ \\
\hline 3 & 6 & 12.1 & $1.35, P<0.001$ & 1.82 & 3.17 & $0.43(0.09)$ \\
\hline 4 & 6 & 7.8 & $0.65, P<0.001$ & 1.85 & 2.50 & $0.26(0.07)$ \\
\hline 5 & 6 & 11.9 & $0.82, P=0.003$ & 2.06 & 2.88 & $0.28(0.12)$ \\
\hline 8 & 4 & 13.7 & $0.84, P=0.001$ & 1.06 & 1.90 & $0.44(0.15)$ \\
\hline 9 & 4 & 11.7 & $1.75, P<0.001$ & 3.52 & 5.27 & $0.33(0.06)$ \\
\hline 10 & 4 & 11.3 & $1.01, P<0.001$ & 2.68 & 3.69 & $0.27(0.06)$ \\
\hline 11 & 10 & 11.0 & $0.78, P<0.001$ & 1.16 & 1.94 & $0.40(0.05)$ \\
\hline 12 & 10 & 10.6 & $1.04, P<0.001$ & 1.01 & 2.05 & $0.51(0.06)$ \\
\hline 13 & 8 & 11.9 & $1.46, P<0.001$ & 1.91 & 3.37 & $0.43(0.07)$ \\
\hline 14 & 6 & 10.7 & $1.57, P<0.001$ & 3.79 & 5.36 & $0.29(0.07)$ \\
\hline 15 & 7 & 10.4 & $1.58, P<0.001$ & 1.14 & 2.72 & $0.58(0.06)$ \\
\hline 16 & 7 & 10.4 & $1.99, P<0.001$ & 2.03 & 4.02 & $0.49(0.07)$ \\
\hline 17 & 6 & 9.3 & $1.08, P<0.001$ & 2.08 & 3.16 & $0.34(0.07)$ \\
\hline 18 & 6 & 8.9 & $0.51, P=0.005$ & 2.91 & 3.42 & $0.15(0.07)$ \\
\hline 19 & 9 & 10.8 & $1.04, P<0.001$ & 1.48 & 2.52 & $0.41(0.06)$ \\
\hline
\end{tabular}

$\widehat{\sigma}_{g}^{2}, \widehat{\sigma}_{e}^{2}, \widehat{\sigma}_{P}^{2}=$ estimated total genetic, environmental and phenotypic variances, respectively; $\widehat{H}^{2}=$ estimated broad-sense heritability. For $\widehat{H}^{2}$, the approximate standard errors are given in parenthesis. The $P$ values refer to likelihood ratio tests, which were carried out to test the departure of $\widehat{\sigma}_{g}^{2}$ from zero.

$0.02, n=8)$ ratios tended to be low compared with the average of the $\widehat{h}^{2}$ values. The average ratio of the nonadditive to additive genetic variance for PIL in the CP trials was $0.30 \pm 0.09$, and to the total genetic variance was $0.21 \pm 0.05$. The average $\widehat{H}^{2}$ for PIL from the six trials on which $\mathrm{UC}$ and $\mathrm{CP}$ material co-occurs was identical for both CP $(0.37 \pm 0.05)$ and UC $(0.37 \pm 0.03)$ material, both of which were higher than the average $\widehat{h}^{2}$ $(0.29 \pm 0.04)$ from the same six trials. Nevertheless, when contrasting individual estimates obtained separately from $\mathrm{CP}$ and UC material tested in the same trial, the differences between $\widehat{h}^{2}$ (Table 3 ) and $\widehat{H}^{2}$ (Table 4) values were generally within the magnitude of the respective standard errors for all trials except trial 2. Similar to DBH, the difference between the averages of $\widehat{h}^{2}$ and $\widehat{H}^{2}$ for PIL across all CP and UC trials (i.e. $\widehat{h}^{2}=0.29 \pm 0.03, n=8$, versus $\left.\widehat{H}^{2}=0.38 \pm 0.03, n=17\right)$ approached the average proportion of the total phenotypic variance due to nonadditive genetic variance, as estimated from the $\mathrm{CP}$ material (i.e. $0.08 \pm 0.02, n=8$ ). Despite their lack of statistical significance in individual CP trials, non-additive genetic effects appear to be as important for PIL as for DBH in these trials in terms of their relative contribution to the total genetic variation (i.e. $0.21 \pm 0.05$ versus $0.17 \pm$ 0.08 ). Most of the non-additive variation for PIL appears to be attributable to $\widehat{I}^{2}$ rather than $\widehat{D}^{2}$, which is very small. Apart from the related study of Costa e Silva et al.( 2004), the only previous reports on the importance of non- additive genetic effects for PIL are for $\widehat{D}^{2}$. These are similarly low compared to additive genetic effects $\left(\widehat{D}^{2}=0.02\right.$ cf. $\widehat{h}^{2}=0.29$, average of eight trials, present study; $\widehat{D}^{2}=0.06 \mathrm{cf}$. $\widehat{h}^{2}=0.30$, average of five trials aged 6 years, Volker 2002; $\widehat{D}^{2}=0.04$ cf. $\widehat{h}^{2}=0.29$, one trial aged 6 years, Volker et al. 2008). Non-additive genetic effects are thought to be small for wood density in eucalypts - a result mainly supported by the absence of inbreeding depression (Hardner and Tibbits 1998) and, in E. globulus, a good correlation between open-pollinated and CP breeding value estimates (Volker 2002; Potts et al. 2004), as well as a report of $\widehat{D}^{2}$ for core basic density by $\mathrm{Li}$ et al. (2007). In the later case, the estimated dominance to additive variance ratio was 0.32 , comparable to our estimate, and not significantly different from zero.

\section{Relationship between diameter and Pilodyn}

The genetic, environmental, and phenotypic correlations between DBH and PIL are listed in Table 5. The general trend indicated by the results is a consistently high and adverse correlation, ranging between 0.20 and 0.85 (mean= $0.64 \pm 0.08, n=8)$ for additive genetic effects $\left(r_{a}\right)$, between 0.30 and 0.88 (mean $=0.58 \pm 0.04, n=17$ ) for total genetic effects $\left(r_{g}\right)$, between -0.01 and 0.64 (mean $=0.38 \pm 0.03, n=$ 25) for environmental effects $\left(r_{e}\right)$, and between 0.06 and 0.63 (mean $=0.43 \pm 0.02, n=25)$ for phenotypic effects $\left(r_{p}\right)$. Statistically significant $(P \leq 0.05)$ correlation coefficients 
Table 5 Estimated additive genetic $\left(r_{a}\right)$, total genetic $\left(r_{g}\right)$, environmental $\left(r_{e}\right)$ and phenotypic $\left(r_{p}\right)$ correlations (with approximate standard errors within parenthesis) between breast-height diameter
(DBH) and Pilodyn readings (PIL), obtained by bivariate analysis of single-site data from E. globulus trials with control-pollinated (CP) material and/or unrelated clones (UC)

\begin{tabular}{|c|c|c|c|c|c|c|c|}
\hline \multirow[t]{2}{*}{ Trial } & \multirow[t]{2}{*}{ Age (years) } & \multicolumn{3}{|c|}{ Correlation estimates from $\mathrm{CP}$ data } & \multicolumn{3}{|c|}{ Correlation estimates from UC data } \\
\hline & & $r_{a}$ & $r_{e}$ & $r_{p}$ & $r_{g}$ & $r_{e}$ & $r_{p}$ \\
\hline 1 & 7 & $0.78(0.12), P<0.001$ & $0.32(0.03)$ & $0.44(0.05)$ & $0.52(0.16), P=0.006$ & $0.21(0.07)$ & $0.35(0.08)$ \\
\hline 2 & 7 (DBH), 4 (PIL) & $0.85(0.12), P<0.001$ & $0.51(0.03)$ & $0.53(0.03)$ & $0.71(0.17), P=0.005$ & $0.44(0.07)$ & $0.49(0.06)$ \\
\hline 3 & 4 (DBH), 6 (PIL) & $0.83(0.22), P<0.001$ & $0.36(0.05)$ & $0.41(0.05)$ & $0.30(0.23), P>0.05$ & $0.44(0.08)$ & $0.38(0.08)$ \\
\hline 4 & 6 & $0.81(0.13), P<0.001$ & $0.56(0.03)$ & $0.59(0.03)$ & $0.59(0.16), P=0.007$ & $0.59(0.04)$ & $0.59(0.05)$ \\
\hline 5 & 6 & $0.65(0.21), P=0.006$ & $0.45(0.05)$ & $0.47(0.05)$ & $0.55(0.27), P>0.05$ & $0.44(0.10)$ & $0.46(0.09)$ \\
\hline 6 & $4(\mathrm{DBH}), 5$ (PIL) & $0.43(0.21), P=0.05$ & $0.40(0.06)$ & $0.39(0.05)$ & NA & NA & NA \\
\hline 7 & 4 (DBH), 5 (PIL) & $0.56(0.22), P=0.018$ & $0.41(0.06)$ & $0.41(0.05)$ & NA & NA & NA \\
\hline 8 & 4 & $0.20(0.16), P>0.05$ & $-0.01(0.06)$ & $0.06(0.05)$ & $0.75(0.24), P=0.019$ & $0.06(0.18)$ & $0.29(0.14)$ \\
\hline 9 & $6(\mathrm{DBH}), 4$ (PIL) & NA & NA & NA & $0.65(0.13), P=0.001$ & $0.64(0.03)$ & $0.63(0.04)$ \\
\hline 10 & 7 (DBH), 4 (PIL) & NA & NA & NA & $0.46(0.18), P=0.034$ & $0.37(0.05)$ & $0.39(0.05)$ \\
\hline 11 & 10 & NA & NA & NA & $0.43(0.14), P=0.007$ & $0.45(0.04)$ & $0.43(0.04)$ \\
\hline 12 & $11(\mathrm{DBH}), 10(\mathrm{PIL})$ & NA & NA & NA & $0.47(0.13), P=0.002$ & $0.38(0.04)$ & $0.42(0.06)$ \\
\hline 13 & 8 & NA & NA & NA & $0.53(0.13), P=0.001$ & $0.16(0.07)$ & $0.33(0.08)$ \\
\hline 14 & 6 & NA & NA & NA & $0.75(0.14), P<0.001$ & $0.54(0.05)$ & $0.57(0.04)$ \\
\hline 15 & 7 & NA & NA & NA & $0.88(0.05), P<0.001$ & $0.40(0.05)$ & $0.58(0.04)$ \\
\hline 16 & 7 & NA & NA & NA & $0.87(0.08), P<0.001$ & $0.43(0.06)$ & $0.54(0.05)$ \\
\hline 17 & 6 & NA & NA & NA & $0.54(0.14), P=0.002$ & $0.32(0.06)$ & $0.38(0.06)$ \\
\hline 18 & $10(\mathrm{DBH}), 6$ (PIL) & NA & NA & NA & $0.45(0.25), P>0.05$ & $0.48(0.07)$ & $0.47(0.06)$ \\
\hline 19 & 9 & NA & NA & NA & $0.46(0.16), P=0.014$ & $0.23(0.03)$ & $0.27(0.05)$ \\
\hline
\end{tabular}

The $P$ values refer to likelihood ratio tests, which were carried out to test the departure of $r_{a}$ or $r_{g}$ from zero. $N A$ not available.

were detected for $r_{a}$ in all trials except trial 8, and for $r_{g}$ in 14 of the 17 estimates calculated.

While $r_{a}$ close to zero (i.e. 0.02 and 0.05 ) were reported by Lopez et al.( 2002), in most cases $r_{a}$ between DBH and PIL tend to be adverse (e.g. 1.24, Dean et al. 1990; range $=$ 0.05 to 0.34 , McDonald et al. 1997 ; range $=0.04$ to 0.85 , Muneri and Raymond 2000; range $=0.34$ to 0.40 , Volker 2002), with the present data being one of the more extreme examples. Additive genetic correlations between DBH and basic density have generally been unfavorable as well, but the relationship tends to be weaker (e.g. -0.47 , Dean et al. 1990; range $=0$ to -0.44 , Muneri and Raymond 2000; -0.58 , Apiolaza et al. 2005). The marked and relatively consistent adverse relationship between DBH and PIL at the genetic, environmental and phenotypic levels in the present case argues for a possible adverse pleiotropic relationship between wood density and growth (a gene affects the two traits because they are intrinsically physiologically related). However, whilst the correlation between basic density and PIL has been reported as high (see "Introduction"), PIL penetration can also be affected by wood anatomy, ring width or within-ring density variation at a given tree age and sampling height. Tree differences in one or all of these factors may have an impact on the estimates of genetic variance for PIL, as well as on its covariances with other traits. Overall, this problem influences the efficiency of multivariate selection indices combining growth and PIL. Therefore, it remains to be clarified whether the magnitude and the tendency of the relationship found here between DBH and PIL can be confirmed for diameter growth and basic density measures obtained from independent CP family trials. This would provide a stronger support for a pleiotropic relationship between wood density and growth.

Pooled analysis for diameter, Pilodyn and pulp yield

Given the sparseness of pulp yield measurements across the CP trials, an analysis using a combined PY data was attempted. The estimated genetic parameters for PY and the correlations of this trait with DBH and PIL are given in Table 6. The pooled $\widehat{h}^{2}$ and $\widehat{H}^{2}$ for DBH (i.e. 0.26 and 0.35 , respectively) and PIL (i.e. 0.37 and 0.41 , respectively) were within the range of values reported previously for the single-trait analysis, in Tables 1 and 3 . Likewise, the correlations between DBH and PIL, estimated from the combined PY data, are also within the range of values shown in Table 5 .

The pooled $\widehat{h}^{2}$ and $\widehat{H}^{2}$ values for PY were 0.42 and 0.51 , respectively (Table 6). Compared to assuming homoge- 
Table 6 Estimated means, variances, derived genetic parameters and between-trait correlations from univariate and bivariate analyses of pulp yield (PY), breast-height diameter (DBH) and Pilodyn readings
(PIL) measured in E. globulus trials with clonally replicated progeny from controlled crosses

\begin{tabular}{llll}
\hline Means, variances and genetic parameters & DBH $(\mathrm{cm})$ & PIL (mm) & PY (\%) \\
Means & 11.2 & 12.0 & 52.2 \\
$\widehat{\sigma}_{a}^{2}$ & $0.96, P=0.005$ & $1.25, P<0.001$ & $1.06, P<0.001$ \\
$\widehat{\sigma}_{D}^{2}$ & $0.35, P>0.05$ & $0.13, P>0.05$ & $a$ \\
$\widehat{\sigma}_{I}^{2}$ & $b$ & $b$ & $0.24, P>0.05$ \\
$\widehat{\sigma}_{e}^{2}$ & 2.40 & 2.02 & 1.25 \\
$\widehat{\sigma}_{P}^{2}$ & 3.71 & 3.40 & 2.55 \\
$\widehat{h}^{2}$ & $0.26(0.12)$ & $0.37(0.16)$ & $0.42(0.14)$ \\
$\widehat{D}^{2}$ & $0.09(0.20)$ & $0.04(0.22)$ & $\mathrm{NE}$ \\
$\widehat{I}^{2}$ & $\mathrm{NE}$ & $\mathrm{NE}$ & $0.09(0.12)$ \\
$\widehat{H}^{2}$ & 0.35 & 0.41 & 0.51 \\
Trait correlations & $\mathrm{DBH}, \mathrm{PIL}$ & $\mathrm{DBH}, \mathrm{PY}$ & $\mathrm{PIL}, \mathrm{PY}$ \\
$r_{a}$ & $0.59(0.20), P=0.002$ & $0.12(0.18), P>0.05$ & $0.05(0.16), P>0.05$ \\
$r_{e}$ & $0.18(0.06)$ & $-0.01(0.06)$ & $-0.10(0.07)$ \\
$r_{p}$ & $0.29(0.05)$ & $0.03(0.06)$ & $-0.03(0.06)$
\end{tabular}

The results are based on an analysis that used a data set combining across trials the information available simultaneously for all traits and assumed no genotype by environment interaction for additive and non-additive genetic effects (see text for further details). $\widehat{\sigma}_{a}^{2}, \widehat{\sigma}_{D}^{2}, \widehat{\sigma}_{I}^{2}, \widehat{\sigma}_{e}^{2}, \widehat{\sigma}_{P}^{2}=$ estimated additive genetic, dominance, epistatic, environmental and phenotypic variances, respectively. $\widehat{h}^{2}, \widehat{D}^{2}, \widehat{I}^{2}=$ estimated narrow-sense heritability, dominance and epistatic ratios, respectively; $\widehat{H}^{2}=\widehat{h}^{2}+\widehat{D}^{2}+\widehat{I}^{2}=$ estimated broad-sense heritability; $r_{a}, r_{e}, r_{p}=$ estimated additive genetic, environmental and phenotypic correlations, respectively. For $\widehat{h}^{2}, \widehat{D}^{2}, \widehat{I}^{2}$ and between-trait correlations, the approximate standard errors are given in parenthesis. The $P$ values refer to likelihood ratio tests, which were carried out to test the departure of $\widehat{\sigma}_{a}^{2}, r_{a}$, as well as the variance specific to full-sib families ( $P$ value in the $\widehat{\sigma}_{D}^{2}$ row) and the variance among clones within full-sib families ( $P$ value in the $\widehat{\sigma}_{I}^{2}$ row), from zero. $N E$ not estimated and assumed to be zero.

${ }^{\mathrm{a}} \widehat{\sigma}_{f}^{2}$ constrained to remain positive at the zero bound.

$\mathrm{b} \widehat{\sigma}_{c}^{2}$ allowed to be negative, but it was close to zero.

neous residual variances (as applied here), a previous analysis of PY that incorporated heterogeneous residual variances across trials (not shown) in the linear mixed model led to similar conclusions in regard to significance tests for additive and non-additive variances, as well as resulted in similar values for the pooled $\widehat{h}^{2}$ and $\widehat{H}^{2}$ (note that, in this case, an average of the residual variances estimated for individual trials was used to calculate the phenotypic variance of PY). There are few reported estimates of narrow-sense heritability of pulp yield in $E$. globulus, and they are all based on open-pollinated material (Dean et al. 1990; Raymond et al. 2001; Apiolaza et al. 2005). The reported values vary between 0.33 and 0.58 , and are close to the estimate found here, suggesting that PY is under a reasonably high level of genetic control. This is an important result since PY is the most important trait for integrated pulp production schemes.

Equally important, the genetic and phenotypic correlations between PY and DBH $\left(r_{a}=0.12 \pm 0.18\right.$ and $\left.r_{p}=0.03 \pm 0.06\right)$, and between PY and PIL $\left(r_{a}=0.05 \pm 0.16\right.$ and $\left.r_{p}=-0.03 \pm 0.06\right)$ were close to zero (Table 6), indicating that PY is independent of the other major selection criteria. The $r_{a}$ between PY and DBH found here differs from those values reported in the literature, which were consistently adverse across the estimates available $\left(r_{a}=-0.54\right.$, Dean et al. $1990 ; r_{a}=-0.16$ and -0.43 ,
Raymond et al. 2001; $r_{a}=-0.16$, Apiolaza et al. 2005). Nevertheless, when presented, estimated standard errors of these reported correlation parameters were high (i.e. varying from 0.24 to 0.48: Raymond et al. 2001; Apiolaza et al. 2005), suggesting that they may not differ significantly from zero. Except for the small study of Dean et al. (1990), where $r_{a}=$ -0.98 , the neutral additive genetic correlation between PY and PIL obtained in the present study is near the estimates previously reported $\left(r_{a}=-0.09,0.18\right.$ and 0.24 , Raymond et al. 1999). The additive genetic correlations between PY and basic density reported in the literature have been highly variable $\left(r_{a}=0.67\right.$, Dean et al. 1990; $r_{a}=0,0.08$ and 0.74, Raymond et al. 2001; $r_{a}=1.08$, Apiolaza et al. 2005), but the general trend is for the two traits to be positively associated. However, some of the high $r_{a}$ values reported between PY and either PIL or basic density were obtained with small sample sizes (e.g. 193 progeny representing 18 open-pollinated parent trees, Dean et al. 1990; 188 progeny representing 35 open-pollinated parent trees, Apiolaza et al. 2005), which may have influenced the precision of the estimates.

Multi-site bivariate analysis of diameter and Pilodyn

The importance of $\mathrm{G} \times \mathrm{E}$ interaction was assessed for $\mathrm{DBH}$ and PIL through the magnitude of a common estimate of 
Table 7 Estimated genetic correlations from bivariate multi-site analysis of breast-height diameter (DBH) and Pilodyn readings (PIL) measured in E. globulus trials with control-pollinated (CP) material and/or unrelated clones (UC), and using all the data available from the eight $\mathrm{CP}$ or seventeen $\mathrm{UC}$ trials

\begin{tabular}{|c|c|c|c|c|}
\hline \multirow[t]{2}{*}{ Plant material } & \multirow[t]{2}{*}{$r_{\mathrm{DBH}}$} & \multirow[t]{2}{*}{$r_{\mathrm{PIL}}$} & \multicolumn{2}{|l|}{$r_{\mathrm{DBH}, \mathrm{PIL}}$} \\
\hline & & & 1 & 2 \\
\hline $\mathrm{CP}$ & $0.83(0.06), P<0.001$ & $0.90(0.05), P=0.002$ & $0.54(0.06)$ & $0.46(0.07)$ \\
\hline $\mathrm{UC}$ & $0.67(0.05), P<0.001$ & $0.80(0.03), P<0.001$ & $0.58(0.05)$ & $0.45(0.06)$ \\
\hline
\end{tabular}

The genetic correlations refer to additive effects for the CP material and to total genetic effects for the UC data. $r_{D B H}$ and $r_{P I L}=$ common estimate of the across-site correlations for a given trait; $r_{D B H}, P I L=$ common estimate of the correlation between traits, both within (denoted 1$)$ and across (denoted 2) sites. The approximate standard errors of the correlation estimates are given in parenthesis. The $P$ values refer to likelihood ratio tests, which were carried out to test the departure of $r_{D B H}$ or $r_{P I L}$ from one. For likelihood ratio tests applied to test whether $r_{D B H}$, PIL was different among 1 and 2, the significance probabilities were $P>0.05$ and $P<0.001$ for the CP and UC sources of plant material, respectively.

the genetic correlation between the performance of the same trait measured in different trials. The results are presented in Table 7.

For both $\mathrm{CP}$ and $\mathrm{UC}$ sources of plant material, the common estimates of the across-site genetic correlations obtained for DBH and PIL were high, although the LR tests indicated that they were differing significantly $(P \leq 0.01)$ from one. The magnitudes of the estimates were particularly high for PIL, with values above 0.8 . The additive genetic correlations (based on the CP families) were higher than the genotypic correlations (based on total genetic effects from the UC material), but the differences were not large.

As expected, the genetic correlations between DBH and PIL were somewhat lower when the two traits were measured in different as compared to the same trials, but the differences were small and only significant $(P<$ 0.001 ) for the UC comparisons (which reflects a greater power of the LR test for the UC material due to a better sample size, e.g. more observations per genotype). The parameter values confirmed the strong unfavourable relationship between DBH and PIL, providing a pooled genetic correlation estimate of around 0.5 for both $\mathrm{CP}$ and UC material.

The results found give strong support to a relatively homogeneous genetic behaviour of E. globulus material across the range of environmental conditions in Portugal. Moderate to low levels of $\mathrm{G} \times \mathrm{E}$ interaction have been reported elsewhere for growth and wood density in $E$. globulus (e.g. Borralho et al. 1992; McDonald et al. 1997; Muneri and Raymond 2000; Costa e Silva et al. 2004, 2006). This result has important implications for selection strategies used in the RAIZ E. globulus breeding program, since it supports the use of single selection criteria for growth and wood density across normal planting environments in Portugal.

\section{Conclusion}

A range of genetic parameters for diameter, Pilodyn penetration and pulp yield in E. globulus was studied. The estimates were based on a set of full pedigree material, including cloned full-sib progeny and unrelated clones. This material was tested across a range of 19 sites, hence providing a complete picture of the pattern of inheritance for the three most important traits in breeding eucalyptus for pulp production. The estimates include the additive genetic variances and covariances, and nonadditive genetic terms such as dominance and epistasis.

Diameter, Pilodyn and pulp yield were all under moderate levels of genetic control. Genetic correlation estimates for the same trait measured across different trials were notably high, suggesting that, for the range of conditions experienced in these trials, genotype by environment interaction is expected to be of modest importance for diameter and Pilodyn, and should have a mild impact on selection.

The most striking result was the moderately strong unfavourable correlation between Pilodyn and diameter. Given the low genetic correlation usually reported between wood density and growth, the impact on efficiency of selecting for productivity and wood density when using Pilodyn becomes a concern. Whatever the causes for this result, it points to a strong adverse relationship between diameter and Pilodyn penetration at the genetic, environmental and phenotypic levels in $E$. globulus. Given the importance of Pilodyn as an indirect method to assess wood density, this issue deserves further investigation. On the other hand, the correlations between pulp yield and either diameter or Pilodyn were close to zero, suggesting that pulp yield is independent of the other major selection criteria. 
Acknowledgement We are indebted to RAIZ for making their breeding trial data available for analysis, and in particular, the contributions from José Luis Amaral, Fernanda Furtado and Mendes de Sousa are gratefully acknowledged. We thank the Australian Research Council for the Linkage grant (LP0453704) that provided support for data analysis and Fundação para a Ciência e Tecnologia (Lisboa, Portugal) for the research grant currently given to the senior author. We also wish to express our gratitude to José Carlos Rodrigues, Rowland Burdon, and three anonymous reviewers for their helpful comments and suggestions on the manuscript.

\section{Appendix 1}

The wood samples for the estimation and prediction of pulp yield using NIR analysis were from 89 trees selected in different geographical regions in Portugal. These regions represented an ample range of site productivities and environmental conditions for growing E. globulus in the country. The age of the selected trees varied between 3 and 11 years old, with their distribution being generally uniform across the age classes. In addition, for a given age, trees varied in their phenotype for growth rate. For kraft pulp yield determinations, wood chips were produced from $50-\mathrm{cm}$ long logs collected at four different height levels in each tree. The logs were cooked in an alkaline solution to a fixed Kappa index of 16 in a laboratory digester. These assessments provided a range for kraft pulp yield of $45.1 \%$ to $57.1 \%$ across trees, with an average of $52.2 \%$. For NIR analysis, a portion (corresponding to a sampling level close to breast height) of the wood chips from each tree was ground to pass a 1-mm screen in a Cyclotec Model 1903 abrasion mill (Foss Tecator, Sweden). The wood meal samples were then kept in a controlled environment (i.e. constant temperature of $23^{\circ} \mathrm{C}$ and relative humidity of $50 \%$ ) for stabilising their moisture content to approximately $10 \%$. The NIR spectra were recorded on a 5-g sample of the wood meal for each tree, using a FT-NIR Bruker Vector 22/N instrument. The spectra were collected at 2-nm intervals over the wavelength range of 1100-2500 nm, with two spectra being recorded per sample. Fifty scans were accumulated per sample, and the results were averaged to produce one spectrum.

The set of 89 samples was split randomly into two subsets: one made of 65 samples (range from $45.9 \%$ to $56.2 \%$ ) to construct a calibration model relating the kraft pulp yield determinations with the NIR spectral data, and the other made of 24 samples (range from $45.1 \%$ to $57.1 \%$ ) for external validation (i.e. to assess the ability of the developed calibration model for predicting pulp yield in wood samples that are different from those used in the calibration group). The software Unscrambler (CAMO, Norway) was used for data analysis. Prior to modelling, the spectral data were converted to the second-derivative mode using the gap-segment algorithm (gap width of $20 \mathrm{~nm}$ ) available in the software. Then, a calibration model relating kraft pulp yield with the secondderivative spectral data was constructed by applying partial least squares (PLS) regression, and using the minimum root mean square error of cross validation as a criterion to retain an optimum number of PLS regression factors in the model. The number of PLS factors retained was 6 , and in terms of data fitting, the PLS calibration model performed well as indicated by a coefficient of determination of calibration of 0.96 and a standard error of calibration of $0.49 \%$. When applied to the set of 24 independent samples, the PLS calibration model provided a standard error of prediction of $0.96 \%$ and led to a correlation between laboratory and NIR-predicted pulp yield of 0.92 . These results suggested that NIR analysis could be used as a reasonably accurate predictor of pulp yield in unknown wood samples (such as those that were subsequently collected in the field trials).

\section{Appendix 2}

Table 8 Number of parents and clones within full-sib families in $E$. globulus trials with clonally replicated progeny from controlled crosses

\begin{tabular}{|c|c|c|c|c|c|c|c|c|}
\hline & 1 & 2 & 3 & 4 & 5 & 6 & 7 & 8 \\
\hline \multicolumn{9}{|c|}{ Parents } \\
\hline 1 & 32 & 32 & 31 & 26 & 31 & 23 & 5 & 14 \\
\hline 2 & & 36 & 34 & 28 & 34 & 24 & 6 & 15 \\
\hline 3 & & & 40 & 30 & 40 & 25 & 7 & 14 \\
\hline 4 & & & & 32 & 30 & 26 & 7 & 12 \\
\hline 5 & & & & & 40 & 25 & 7 & 14 \\
\hline 6 & & & & & & 62 & 40 & 38 \\
\hline 7 & & & & & & & 48 & 34 \\
\hline 8 & & & & & & & & 55 \\
\hline \multicolumn{9}{|c|}{ Clones } \\
\hline 1 & 135 & 133 & 57 & 36 & 58 & 21 & 0 & 6 \\
\hline 2 & & 210 & 81 & 52 & 81 & 30 & 0 & 7 \\
\hline 3 & & & 133 & 51 & 130 & 34 & 0 & 5 \\
\hline 4 & & & & 86 & 51 & 21 & 0 & 4 \\
\hline 5 & & & & & 134 & 34 & 0 & 5 \\
\hline 6 & & & & & & 152 & 58 & 14 \\
\hline 7 & & & & & & & 249 & 21 \\
\hline 8 & & & & & & & & 263 \\
\hline
\end{tabular}

The diagonal elements refer to the number of genetic entries in each trial, and the off-diagonal elements pertain to the number of common entries across trials. 


\section{Appendix 3}

Table 9 Number of clones in E. globulus trials with unrelated clones

\begin{tabular}{|c|c|c|c|c|c|c|c|c|c|c|c|c|c|c|c|c|c|}
\hline & 1 & 2 & 3 & 4 & 5 & 8 & 9 & 10 & 11 & 12 & 13 & 14 & 15 & 16 & 17 & 18 & 19 \\
\hline 1 & 37 & 36 & 16 & 13 & 16 & 10 & 26 & 25 & 1 & 2 & 2 & 2 & 1 & 1 & 9 & 9 & 15 \\
\hline 2 & & 37 & 17 & 14 & 17 & 11 & 27 & 25 & 1 & 3 & 3 & 3 & 2 & 2 & 8 & 8 & 15 \\
\hline 3 & & & 31 & 19 & 31 & 7 & 18 & 17 & 3 & 5 & 5 & 5 & 5 & 5 & 5 & 5 & 7 \\
\hline 4 & & & & 30 & 19 & 7 & 18 & 18 & 5 & 7 & 7 & 7 & 6 & 6 & 5 & 5 & 7 \\
\hline 5 & & & & & 31 & 7 & 18 & 17 & 3 & 5 & 5 & 5 & 5 & 5 & 5 & 5 & 7 \\
\hline 8 & & & & & & 25 & 9 & 9 & 4 & 7 & 7 & 7 & 7 & 7 & 8 & 8 & 5 \\
\hline 9 & & & & & & & 40 & 38 & 3 & 4 & 4 & 4 & 3 & 3 & 10 & 10 & 15 \\
\hline 10 & & & & & & & & 40 & 4 & 4 & 4 & 4 & 3 & 3 & 11 & 11 & 15 \\
\hline 11 & & & & & & & & & 64 & 18 & 18 & 18 & 15 & 13 & 13 & 13 & 0 \\
\hline 12 & & & & & & & & & & 51 & 50 & 48 & 27 & 27 & 21 & 21 & 0 \\
\hline 13 & & & & & & & & & & & 50 & 48 & 27 & 27 & 21 & 21 & 0 \\
\hline 14 & & & & & & & & & & & & 48 & 27 & 27 & 21 & 21 & 0 \\
\hline 15 & & & & & & & & & & & & & 53 & 41 & 20 & 20 & 0 \\
\hline 16 & & & & & & & & & & & & & & 41 & 20 & 20 & 0 \\
\hline 17 & & & & & & & & & & & & & & & 70 & 68 & 7 \\
\hline 18 & & & & & & & & & & & & & & & & 69 & 7 \\
\hline 19 & & & & & & & & & & & & & & & & & 36 \\
\hline
\end{tabular}

The diagonal elements refer to the number of genetic entries in each trial, and the off-diagonal elements pertain to the number of common entries across trials.

\section{References}

Apiolaza LA, Raymond CA, Yeo BJ (2005) Genetic variation of physical and chemical wood properties of Eucalyptus globulus. Silvae Genet 54:160-166

Baltunis BS, Wu HX, Dungey HS, Mullin TJ, Brawner JT (2008) Comparisons of genetic parameters and clonal value predictions from clonal trials and seedling base population trials of radiata pine. Tree Genetics and Genomes. doi:10.1007/s11295-008-0172-y

Borralho NMG, Almeida IM, Cotterill PP (1992) Genetic control of growth of young Eucalyptus globulus clones in Portugal. Silvae Genet 41:100-105

Borralho NMG, Cotterill PP, Kanowski PJ (1993) Breeding objectives for pulp production of Eucalyptus globulus under different industrial cost structures. Can J For Res 23:648-656

Burdon RD, Shelbourne CJA (1974) The use of vegetative propagules for obtaining genetic and physiological information. N Z J For Sci 4:418-425

Callister AN, Collins SL (2008) Genetic parameter estimates in a clonally replicated progeny test of teak (Tectona grandis Linn. F.). Tree Genetics and Genomes 4:237-245

Chambers PGS, Borralho NMG (1997) Importance of survival in short-rotation tree breeding programs. Can J For Res 27:911-917

Chang HL, Fernando RL, Gianola D (1990) An evaluation of maximum likelihood estimates of non-additive genetic variances. In: Hill WC, Thompson R, Wooliams JA (eds) Proceedings 4th World Congress Genet. Appl. Livest. Prod., Edinburgh, Scotland, XIII, pp 437-440

Costa e Silva J, Borralho NMG, Potts BM (2004) Additive and nonadditive genetic parameters from clonally replicated and seedling progenies of Eucalyptus globulus. Theor Appl Genet 108:11131119

Costa e Silva J, Dutkowski GW, Borralho NMG (2005) Across-site heterogeneity of genetic and environmental variances in the genetic evaluation of Eucalyptus globulus trials for height growth. Ann For Sci 62:183-191

Costa e Silva J, Potts BM, Dutkowski GW (2006) Genotype by environment interaction for growth of Eucalyptus globulus in Australia. Tree Genetics and Genomes 2:61-75

Dean GH, French J, Tibbits WN (1990) Variation in pulp and papermaking characteristics in a field trial of Eucalyptus globulus. In: 44th Appita Annual General Conference, Rotorua, New Zealand, April 1990

Downes GM, Catela F, Meder R (2007) Developing and evaluating a global NIR calibration for the prediction of kraft pulp yield in eucalypts. In: Eucalypts and Diversity: Balancing Productivity and Sustainability, IUFRO conference, Durban, South Africa, 22-26 October 2007 (CD-Rom)

Dutkowski GW, Potts BM (1999) Geographic patterns of genetic variation in Eucalyptus globulus ssp. globulus and a revised racial classification. Aust J Bot 47:237-263

Eldridge K, Davidson J, Harwood C, van Wyk G (1993) Eucalypt domestication and breeding. Clarendon, Oxford, UK

Falconer DS, Mackay TFC (1996) Introduction to quantitative genetics. Addison Wesley Longman Limited, Edinburgh Gate, Harlow, UK

Freeman JS, Marques CMP, Carocha V, Borralho NMG, Potts BM, Vaillancourt RE (2007) Origins and diversity of the Portuguese Landrace of Eucalyptus globulus. Ann For Sci 64:639-647

Gilmour AR, Thompson R, Cullis BR (1995) Average information REML. An efficient algorithm for variance parameter estimation in linear mixed models. Biometrics 51:1440-1450 
Gilmour AR, Gogel BJ, Cullis BR, Welham SJ, Thompson R (2002) ASReml user guide release 1.0. VSN International Ltd, Hemel Hempstead, UK

Greaves BL, Borralho NMG, Raymond CA, Evans R, Whiteman PH (1996) Age-age correlations in, and relationships between basic density and growth in Eucalyptus nitens. Silvae Genet 46:264-270

Greaves BL, Borralho NMG, Raymond CA (1997) Breeding objective for plantation eucalypts grown for production of kraft pulp. For Sci 43:465-472

Griffing B (1956) Concept of general and specific combining ability in relation to diallel crossing systems. Aust J Biol Sci 9:463-493

Hardner CM, Potts BM (1995) Inbreeding depression and changes in variation after selfing Eucalyptus globulus subsp. globulus. Silvae Genet 44:46-54

Hardner CM, Tibbits WN (1998) Inbreeding depression for growth, wood and fecundity traits in Eucalyptus nitens. For Genet 5:11-20

Henderson CR (1984) Applications of linear models in animal breeding. University of Guelph, Guelph, Ontario

Hodge GR, Volker PW, Potts BM, Owen JV (1996) A comparison of genetic information from open-pollinated and control-pollinated progeny tests in two eucalypt species. Theor Appl Genet 92:5363

Kumar S (2006) Correlation between clonal means and openpollinated seedling progeny means and its implications for radiata pine breeding strategy. Can J For Res 36:1968-1975

Li Y, Dutkowski GW, Apiolaza LA, Pilbeam DJ, Costa e Silva J, Potts BM (2007) The genetic architecture of a Eucalyptus globulus full-sib breeding population in Australia. For Genet 12:167-179

Libby WJ, Jund E (1962) Variance associated with cloning. Heredity 17:533-540

Lopez GA, Potts BM, Dutkowski GW, Apiolaza LA, Gelid PE (2002) Genetic variation and inter-trait correlations in Eucalyptus globulus base population trials in Argentina. For Genet 9:217-231

Lynch M, Walsh B (1998) Genetics and analysis of quantitative traits. Sinauer Associates, Sunderland, MA, USA

McDonald AC, Borralho NMG, Potts BM (1997) Genetic variation for growth and wood density in Eucalyptus globulus ssp. globulus in Tasmania (Australia). Silvae Genet 46:236-241

Mullin TJ, Park YS (1992) Estimating genetic gains from alternative breeding strategies for clonal forestry. Can J For Res 22:14-23

Muneri A, Raymond CA (2000) Genetic parameters and genotype by environment interactions for basic density, pilodyn penetration and stem diameter in Eucalyptus globulus. For Genet 7:317-328

Núñez-Regueira L, Proupín-Castiñeiras J, Rodríguez-Añón JA (2002) Energy evaluation of forest residues originated from Eucalyptus globulus Labill in Galicia. Bioresour Technol 82:5-13

Patterson HD, Thompson R (1971) Recovery of inter-block information when block sizes are unequal. Biometrika 58:545-554

Potts BM, Jordan GJ (1994) The spatial pattern and scale of variation in Eucalyptus globulus ssp globulus: variation in seedling abnormalities and early growth. Aust J Bot 42:471-492

Potts BM, Vaillancourt RE, Jordan GJ, Dutkowski GW, Costa e Silva J, McKinnon GE, Steane DA, Volker PW, Lopez GA, Apiolaza LA, Li Y, Marques CMP, Borralho NMG (2004) Exploration of the Eucalyptus globulus gene pool. In: Borralho NMG, Pereira JS, Marques CMP, Coutinho J, Madeira M, Tomé M (eds)
Eucalyptus in a changing world. Proceedings IUFRO Conference, Aveiro, Portugal, 11-15 October 2004. RAIZ (Instituto Investigação de Floresta e Papel), Portugal, pp 46-61

Potts BM, McGowen MH, Williams DR, Suitor S, Jones TH, Gore PL, Vaillancourt RE (2008) Advances in reproductive biology and seed production systems of Eucalyptus: the case of Eucalyptus globulus. Southern Forests 70:145-154

Raymond CA (2002) Genetics of Eucalyptus wood properties. Ann For Sci 59:525-531

Raymond CA, Apiolaza LA (2004) Incorporating wood quality and deployment traits in Eucalyptus globulus and Eucalyptus nitens. In: Walter C, Carson M (eds) Plantation forest biotechnology for the 21 st Century. Forest Research New Zealand, Rotorua, New Zealand, pp 87-99

Raymond CA, Muneri A, MacDonald AC (1998) Non-destructive sampling for basic density in Eucalyptus globulus and E. nitens. Appita J 51:224-228

Raymond CA, Schimleck LR, Muneri A, Michell AJ (1999) Genetic parameters and genotype by environment interactions for predicted pulp yield and pulp productivity in Eucalyptus globulus. CRC-SPF Technical Report 16 (CRC-SPF, Hobart, Australia)

Raymond CA, Schimleck LR, Muneri A, Michell AJ (2001) Genetic parameters and genotype by environment interactions for pulp yield predicted using near infrared reflectance analysis and pulp productivity in Eucalyptus globulus. For Genet 8:213-224

Schimleck LR, Raymond CA, Beadle CL, Downes GM, Kube PD, French J (2000) Applications of NIR spectroscopy to forest research. Appita J 53:458-464

Stonecypher RW, McCullough RB (1986) Estimates of additive and non-additive variances from a clonal diallel of Douglas-fir Pseudotsuga menziesii (Mirb.) Franco. In: Proceedings IUFRO Joint Meeting of Working Parties on Breeding Theory, Progeny Testing and Seed Orchards, 13-17 October 1986, Williamsburg, VA. North Carolina State University-Industry Cooperative Tree Improvement Program, Raleigh, pp 211-227

Stram DO, Lee JW (1994) Variance components testing in the longitudinal mixed effects model. Biometrics 50:1171-1177

Vaillancourt RE, Potts BM, Watson M, Volker PW, Hodge GR, Reid JB, West AK (1995) Detection and prediction of heterosis in Eucalyptus globulus. For Genet 2:11-19

Volker PW (2002) Quantitative genetics of Eucalyptus globulus, E. nitens and their $\mathrm{F} 1$ hybrid. Ph.D. thesis, University of Tasmania

Volker PW, Potts BM, Borralho NMG (2008) Genetic parameters of intra- and inter-specific hybrids of Eucalyptus globulus and E. nitens. Tree Genetics and Genomes 4:445-460

Weng YH, Park YS, Krasowski MJ, Tosh KJ, Adams G (2008) Partitioning of genetic variance and selection efficiency for alternative vegetative deployment strategies for white spruce in Eastern Canada. Tree Genetics and Genomes 4:809-819

Whittock SP, Dutkowski GW, Greaves BL, Apiolaza LA (2007) Integrating revenues from carbon sequestration into economic breeding objectives for Eucalyptus globulus pulpwood production. Ann For Sci 64:239-246

Williams ER, Matheson AC (1994) Experimental design and analysis for use in tree improvement. CSIRO, Melbourne, Australia

Zobel B, Sprague J (1998) Juvenile wood in forest trees. Springer, New York, USA 